\title{
Spatio-Temporal Distribution of Malaria in Perak, Malaysia
}

\author{
Norzawati Yoep1, Hazrin Hasim¹, Ummi Nadiah Yusoff', Mahani Yusoff², \\ Noor Rizawati Mahpot ${ }^{2}$ \\ ${ }^{1}$ Institute for Public Health, Ministry of Health, Kuala Lumpur, Malaysia \\ ${ }^{2}$ Vector Borne Disease Control Unit, Perak State Health Department, Ministry of Health, Ipoh, Malaysia \\ Email: norzawati@moh.gov.my
}

Received 26 September 2015; accepted 27 November 2015; published 30 November 2015

Copyright (C) 2015 by authors and Scientific Research Publishing Inc.

This work is licensed under the Creative Commons Attribution International License (CC BY). http://creativecommons.org/licenses/by/4.0/

(c) ()) Open Access

\begin{abstract}
Malaria incidence in Perak, Malaysia has generally declined, but there remain regions of high incidence. The spatio-temporal distribution pattern of malaria in Perak was studied using Geographical Information Systems (GIS) and spatial statistical tools. Malaria data cases at the subdistrict level in Perak from 2007 to 2011 were analysed to determine the spatial and temporal distribution patterns of malaria incidence. Geographical Information Systems (GIS) and spatial statistical tools were used to identify spatial correlation in the data and malaria hot-spots. Spatial correlation was tested by using an autocorrelation method called Moran's I. Hot spot analysis was done using Getis-Ord $G^{*}$ statistic technique. Malaria incidence rates were categorized into 3 classes to map the spatial distribution. Malaria cases in Perak were geo-spatially clustered. Most of the hot spots locations were in Kenering, Ulu Kinta, Gerik and Kampar sub-districts. The prevalence of malaria among foreigners was noticeably higher than Malaysians. Improved surveillance of foreign workers can prevent outbreaks and identify high risk areas. This study implies that geographic-based mapping and information system are needed for an effective malaria control.
\end{abstract}

\section{Keywords}

Malaria, Spatial, GIS, Geocoding

\section{Introduction}

Malaria is one of the most deadly vector-borne diseases in the world. In 2010, there were about 216 million malaria cases worldwide, with an estimated death of 655,000 [1]. While malaria rates are declining worldwide, there remain geographic regions where incidence rates remain high. Similarly, in Malaysia overall rates of mala- 
ria have declined over the past decade [1], but in rural areas like Sabah, Sarawak, and Perak the incidence remains high [2]. Malaysia is currently moving towards malaria elimination [1] and control of malaria outbreaks in high risk areas is the key to achieve this goal. Since malaria incidence is geographically clustered in rural regions, mapping the location of disease-occurrence can be used to identify high-risk areas for prevention activities. Geographic information systems (GIS) have emerged as a new way to collect and manage outbreak data related to location and time.

Traditionally, malaria occurrence was described as the ratio of case numbers at a particular time to the median of past case occurrences [3]. However, since malaria cases vary from one place to another, the spatial and time components must also be taken into consideration to obtain a complete picture of the incident. Spatio-temporal interactions among health events are an important component in epidemiological and public health study. In public health, spatial analysis is used to detect and quantify the patterns of disease distribution that may offer an insight into a disease's epidemiology [4]. Although spatial analytical techniques rarely give reasons for why spatial patterns occur, they are able to identify the locations of cases and can provide a useful means to hypothesize about the health outcomes [5].

Many spatio-temporal studies on infectious diseases such as typhoid and dengue had been carried out in Malaysia [6]-[8], but very few on spatio-temporal studies on malaria. Thus, in this study a spatial analysis was applied in order to map the spatial distribution of malaria cases in Perak.

\section{Methodology}

\subsection{Study Area}

Perak is one of fourteen states in Malaysia, and consists of nine districts: i.e. Hilir Perak, Batang Padang, Manjung, Perak Tengah, Kinta, Kerian, Larut Matangdan Selama, Kuala Kangsar and Hulu Perak. Perak is located at the northern region of Peninsular Malaysia and is the country's fourth largest state $\left(20,963.7 \mathrm{~km}^{2}\right)$, with a total population of 2,253,765 people in 2010 (Figure 1).

\subsection{Data Collection}

Data associated with microscopically confirmed malaria cases between 2002 and 2011 was obtained from the Perak State Health Department to analyze the dynamics of malaria incidence. The recorded number of foreigner malaria cases was also collected. Sub-district level malaria cases covering 83 sub-districts from 2007 to 2011 were compiled for spatial analysis.

\subsection{Implementation of GIS and Spatial Analysis}

In this study, the spatial distribution of malaria incidence in Perak was examined using ArcGIS 10.0 [9] to perform spatial statistic analysis. Previously, transition probability models, which describe temporal transition of a variable from one nominal value (or state) to another, have been used to characterize outbreak patterns of infectious diseases from historical data [10].

We tested for spatial correlation in Perak's malaria cases using an autocorrelation method called Moran's I. Moran's I measures spatial autocorrelation and it is usually applied to area units where numerical ratio or interval data are available [11].

Hot spot analysis using Getis-OrdGi ${ }^{*}$ statistic technique was carried out. The results of z-scores and p-values indicate the high or low value clusters spatially [12]. This tool works by looking at each feature within the context of neighbouring features. A feature with a high value is interesting but may not be a statistically significant hot spot. To be a statistically significant hot spot, a feature will have a high value and surrounded by other features with high values as well. The local sum for a feature and its neighbours are compared proportionally to the sum of all features; when the local sum is very different from the expected local sum, and that difference is too large to be the result of random chance, statistically significant z-score results [3].

The malaria incidence rate was categorized into three classes: 0 cases (class 1), 0 to 1 cases (class 2), and $>1$ cases (class 3) per 1000 population. These classes were also being used by Ministry of Health to classify the areas of malaria burden. The distribution of malaria from the year 2007 to 2011 was mapped according to the classes. 


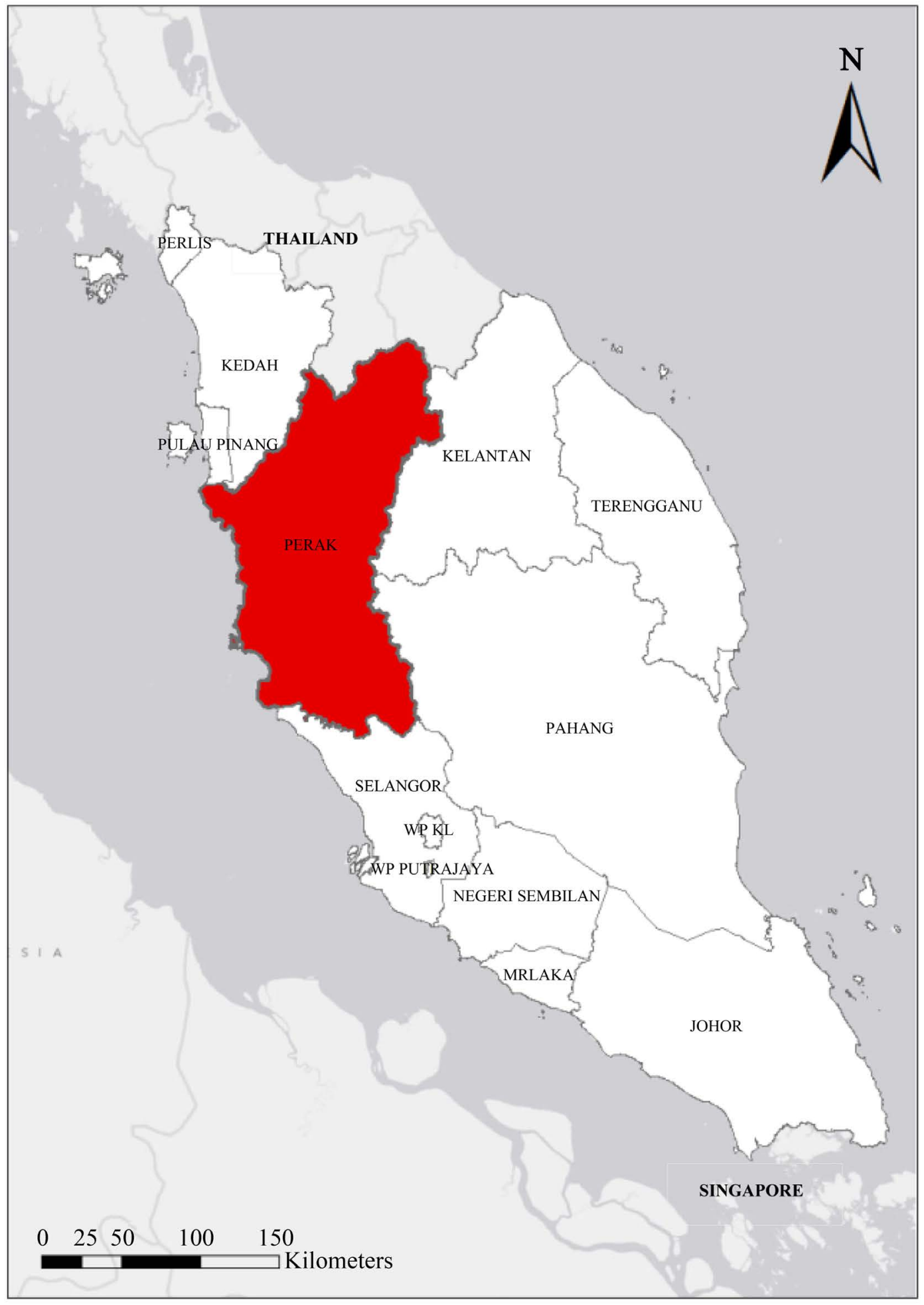

Figure 1. Location of Perak State, Malaysia.

\section{Results}

A total of 1478 malaria cases were reported between 2002 to 2011 in Perak. Malaria cases in Perak showed an overall decline over the past decade except a noticeable increase in 2007 (Figure 2). Additionally, in the past 10 
years, there has been an increase in the proportion of malaria cases among foreigners (Figure 3).

To assess the spatial distribution of malaria cases in the sub-districts of Perak, we used Moran's I as an index of spatial autocorrelation. Results from Moran's I test on malaria incidence for Perak indicated that there was positive spatial autocorrelation in malaria incidence within sub-districts. The Moran's I for malaria cases was 0.03 ( $\mathrm{p}<0.01)$ while the $\mathrm{z}$-score was $3.38(\mathrm{p}<0.01)$. Thus, the spatial distribution of malaria cases in the district is spatially clustered. Figure 4 shows the result of Moran's I analysis.

Hot spot analysis using GetisOrd-Gi ${ }^{*}$ statistic estimation was applied in this study to locate "hot spots" for malaria cases in Perak. The red colored areas in Figure 5 represent hot spots of malaria incidence density. Using a malaria density map, we were able to target specific areas within Perak that show the highest incidence of cases.

Most of the hot spot locations were in Kenering and Ulu Kinta sub-districts. However, it was also found that there were two locations of high malaria density located in the sub-districts of Gerik and Kampar.

The sub-districts of Perak were divided into three classes based on malaria incidence rates (Figure 6). Class 1 represents malaria-free areas, class 2 represents areas of medium incidence rates and class 3 represents areas of the highest incidence rates. The areas in class 3 were located mainly along the north and northwest areas of the state.

\section{Malaria Cases in Perak 2002 - 2011}

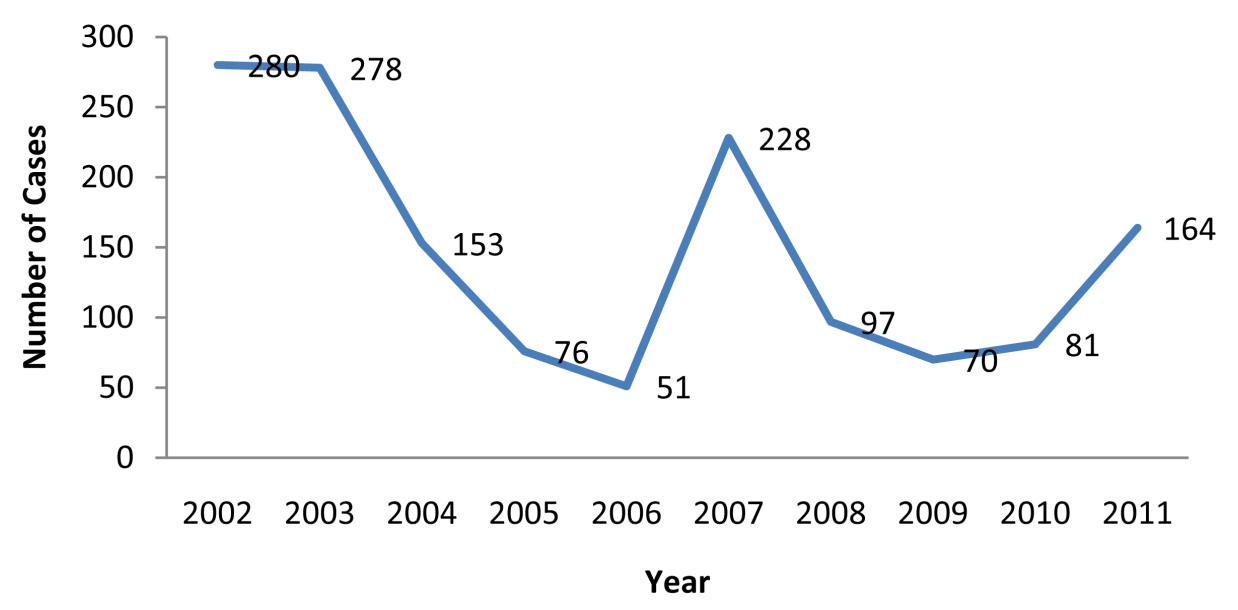

Figure 2. Malaria cases in Perak between 2002-2011.

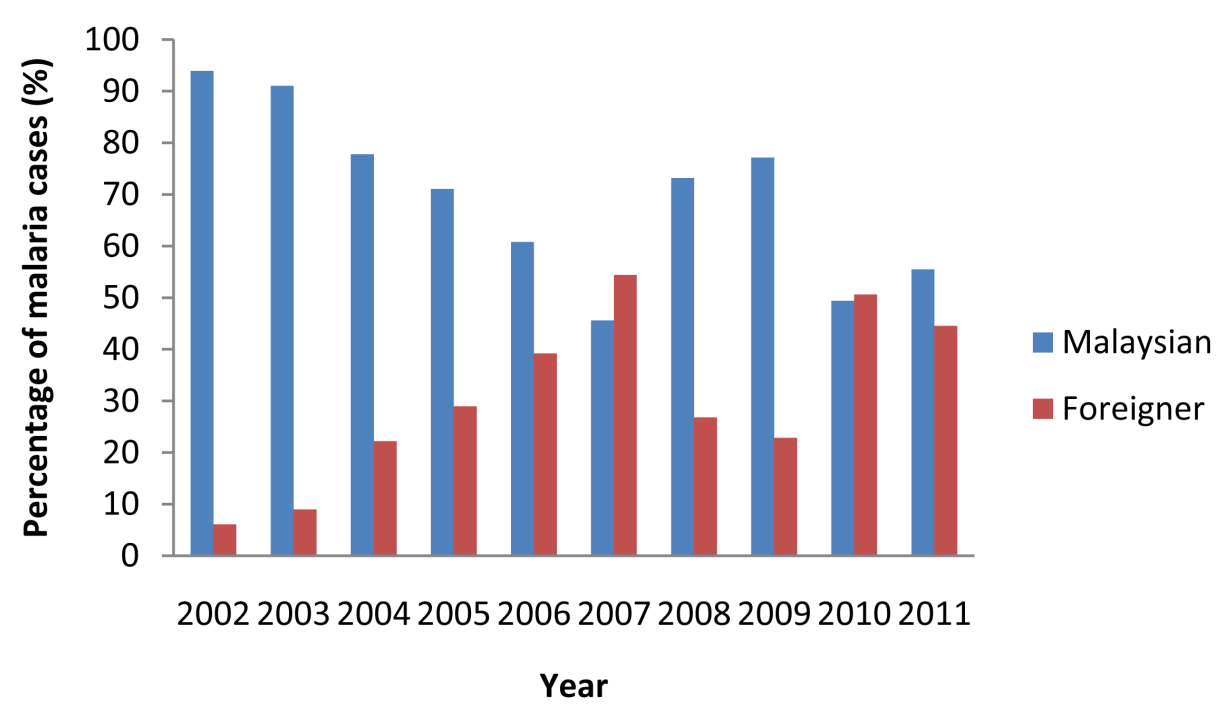

Figure 3. Proportion of malaria cases among foreigners and Malaysians (2002-2011). 


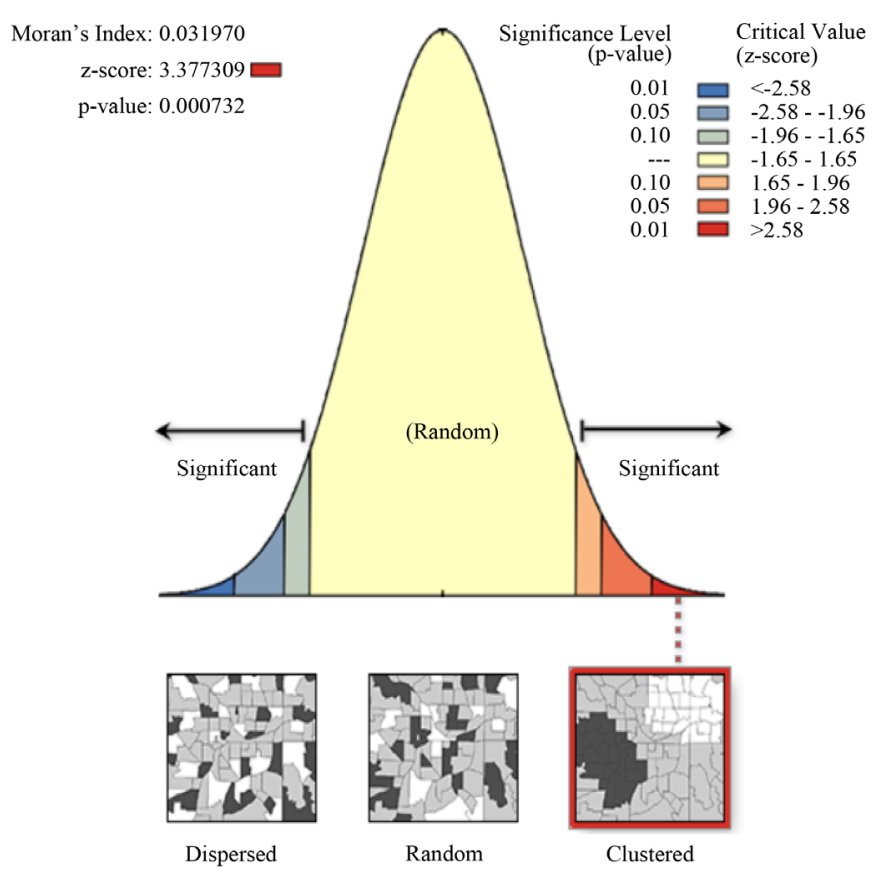

Figure 4. Result of Moran’s I analysis.

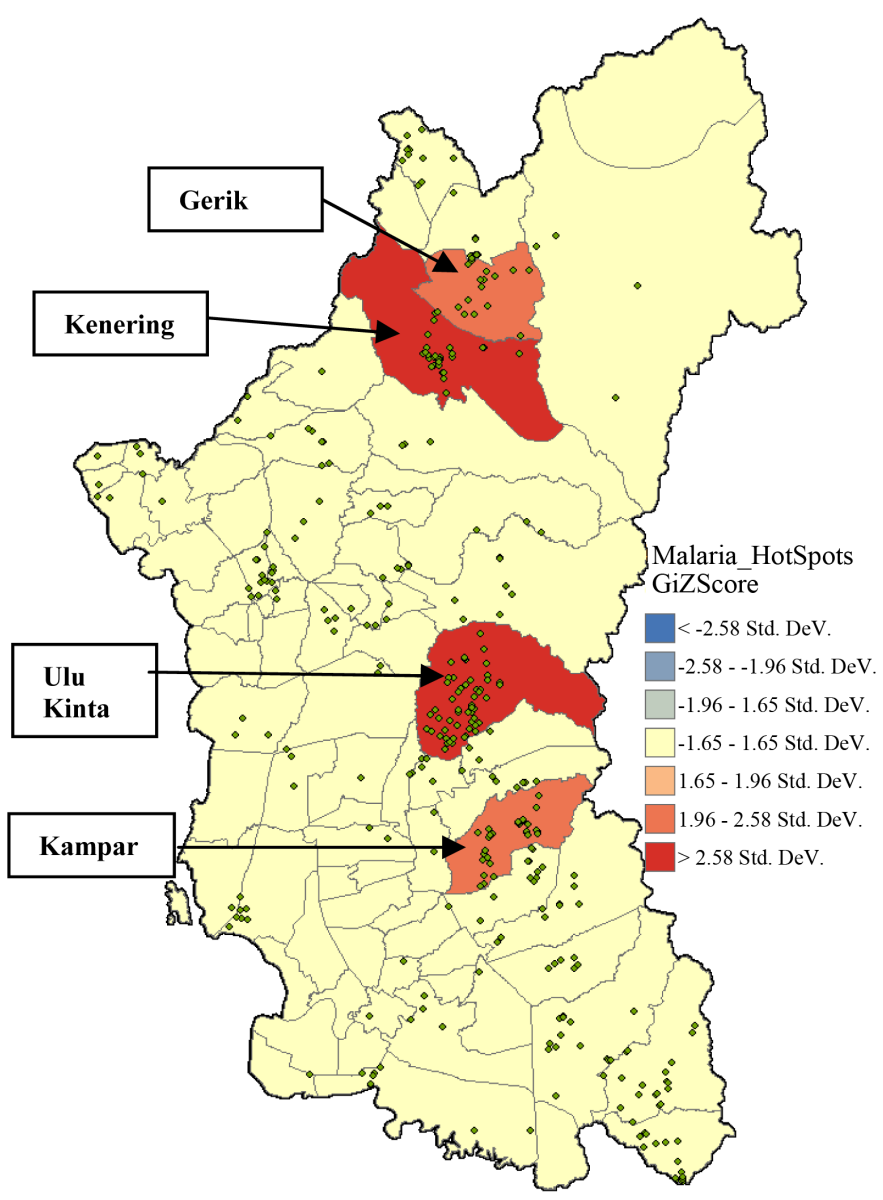

Figure 5. Hot spots of malaria incidence density. 

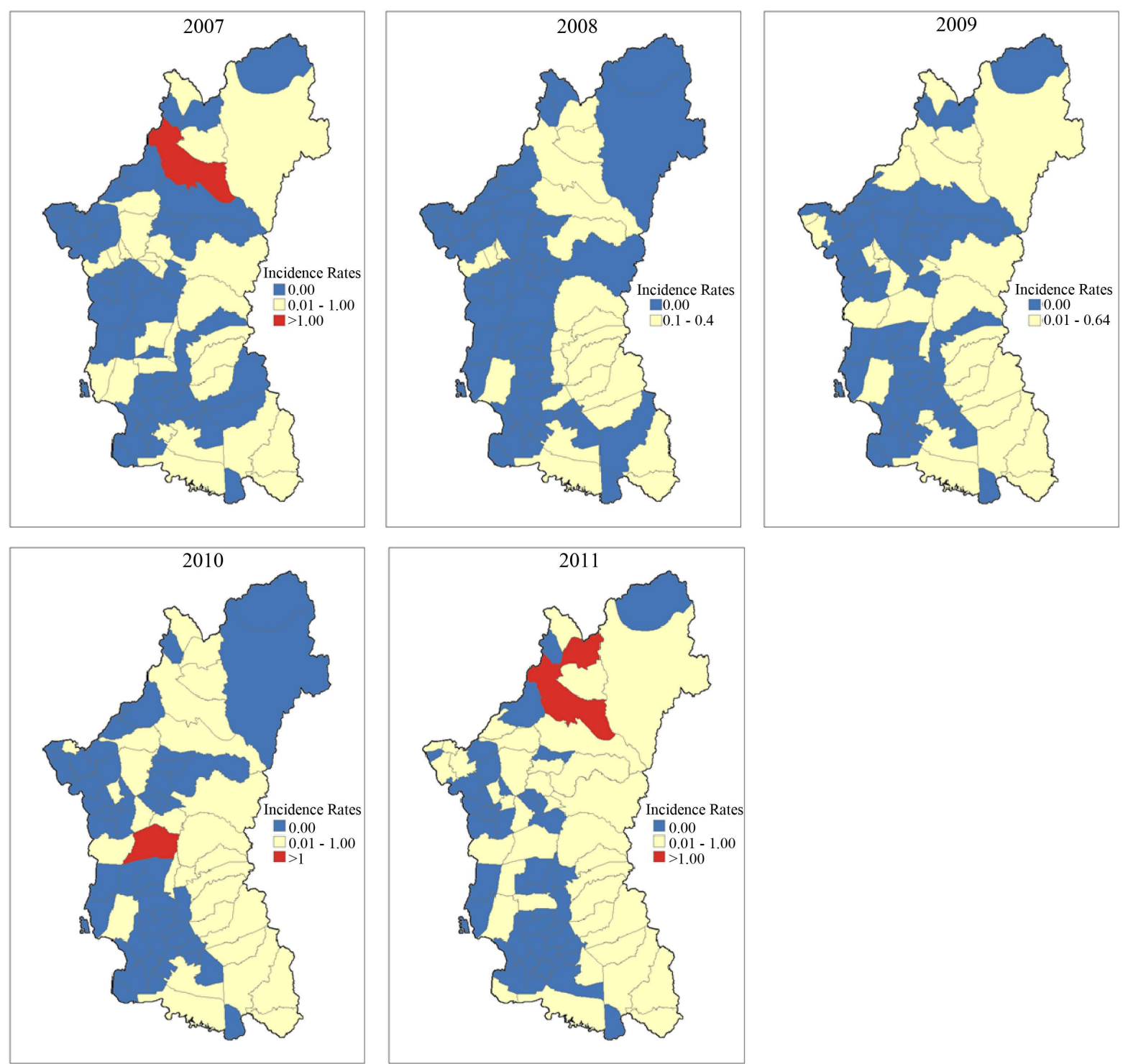

Figure 6. Dynamics of spatial distribution of malaria incidence rates (number of cases per 1000 population) at the subdistrict level from 2007 to 2011.

\section{Discussion}

A retrospective analysis of malaria incidence for the past decade in Perak was performed. The marked increase of cases in the years 2007 and 2011 was due to localised outbreaks in the Kenering sub-district. Interestingly, one of the outbreak areas had been malaria free since 1998 [13]. Reintroduction of the disease could have been caused from numerous factors. These factors included weather conditions, the presence of competent malaria vectors, reintroduction of malaria parasites through human hosts, or through the proximity to malaria endemic countries [14] such as, Thailand.

As presented in Figure 3, a higher prevalence of malaria was found among foreigners, as compared to Malaysians. Over the years, the number of foreign workers in Malaysia has increased [15]. Foreigners who are working in Malaysia on a long term basis are required to apply for working permits. In order to get the permit, they have to undergo screening procedures to ensure that they are free from any infectious diseases. Temporary foreign workers from Thailand are not subjected to this screening. Though these workers may test negative for malaria, upon relapse or asymptomatic malaria, they can be an active carrier. This poses a threat as they are frequently employed in palm oil and rubber plantations where the malaria vectors are abundant. Improved surveil- 
lance of foreign workers can prevent outbreaks and identify high risk areas.

Our result showed that the malaria incidence in Perak occurred in geographic clusters. This is in consistent with previous findings that infectious diseases spread in cluster spatio-temporally [8] [16] [17]. Although a gradual decrease in malaria cases throughout the state had been observed over this period, there were still subdistricts with high malaria incidence. In general, these are the areas with high vector population and high number of foreign workers employed in the agricultural sector.

For this study, malaria incidence in Perak was mapped at the sub-district levels. Malaria needs to be mapped on many different layers, from country level down to village level for a quality control measures. Even in small area, malaria incidence has a significant spatial and temporal heterogeneity on the finer spatial and temporal scales [18]. The distribution of malaria vectors also needs to be mapped as it will provide valuable data on where the species occur. Accurate information on the distribution of malaria permits interventions to be targeted to the foci of transmission and the locations of high malaria risk within them [19]. A working dynamic, geographic-based mapping and information system will enable the integration of malarial control efforts and epidemiologic data to guide management of the disease and its impact at local and countrywide levels [20]. Thus, further studies should be carried out to identify malaria vectors distribution and risk factors for malaria transmission.

\section{Acknowledgements}

Our gratitude goes to the Director General Health of Health Malaysia for his permission to publish this study.

\section{References}

[1] WHO (2011) World Malaria Report.

[2] Ministry of Health (MOH) (2009) Annual Report Putrajaya: Ministry of Health Malaysia.

[3] Mitchell, A. (2005) The ESRI Guide to GIS Analysis. Vol. 2, Spatial Measurements and Statistics. ESRI Press.

[4] Fotheringham, A.S., Brunsdon, C., et al. (2002) Geographically Weighted Regression: The Analysis of Spatially Varying Relationships. Wiley.

[5] Srividya, A., Michael, E., Palaniyandi, M., Pani, S.P. and Das, P.K. (2002) A Geostatistical Analysis of the Geographic Distribution of Lymphatic Filariasis Prevalence in Southern India. American Journal of Tropical Medicine and Hygeine, 67, 480-489.

[6] Shah, S.A., Suzuki, H., Hassan, M.R., Sato, R., Safian, N. and Idrus, S. (2012) Spatial Analysis of Environmental Factors Influencing Typhoid Endemicity in Kelantan, Malaysia. Sains Malaysiana, 41, 911-919.

[7] Safian, N., Shah, S.A., Idrus, S. and Hamzah, W.M. (2008) Cluster Analysis of Thypoid Cases in Kota Bharu, Kelantan, Malaysia. Medical Journal of Indonesia, 7, 175-182. http://dx.doi.org/10.13181/mji.v17i3.319

[8] Aziz, S., Ngui, R., Lim, Y.A.L., Solehan, I., NurFarhana, J., Azizan, A.S. and Wan Yusoff, W.S. (2012) Spatial Pattern of 2009 Dengue Distribution in Kuala Lumpur Using GIS Application. Tropical Biomedicine, 29, 113-120.

[9] ESRI (2011) ArcGIS Desktop: Release 10. Enviromental Systems Research Institute, Redlands.

[10] Wen, T.-H., Lin, N.H., Chao, D.-Y., Hwang, K.-P., Kan, C.-C., Lin, K.C.-M., et al. (2010) Spatial-Temporal Patterns of Malaria in Areas at Risk of Malaria Hemorrhagic Fever in Kaohsiung, Taiwan, 2002. International Journal of Infectious Diseases, 14, e334-e343. http://dx.doi.org/10.1016/j.ijid.2009.06.006

[11] Cliff, A.D. and Ord, J.K. (1981) Spatial Process: Models and Applications. Pion, London.

[12] Getis, A. and Ord, J.K. (1992) The Analysis of Spatial Association by Use of Distance Statistics. Geographical Analysis, 24, 189-206. http://dx.doi.org/10.1111/j.1538-4632.1992.tb00261.x

[13] Noor Asmah, A.S.A., Razin, M., Ranjit, K. and Junaidi, I. (2007) Malaria Outbreak in Hulu Perak District (26 March-25 May 2007). Perak State Health Department Technical Report, 34-44.

[14] Konchom, S., Singhasivanon, P., Kaewkungwal, J., Chupraphawan, S., Thimasarn, K., Kidson, C., Rojanawatsirivet, C., Yimsamran, S. and Looareesuwan, S. (2003) Trend of Malaria Incidence in Highly Endemic Provinces along the Thai Borders, 1991-2001. The Southeast Asian Journal of Tropical Medicine and Public Health, 34, 486-494.

[15] Department of Statistics, Malaysia (2012) Labour Force Statistics, Malaysia. http://www.statistics.gov.my

[16] Zhou, G., Sirichaisinthop, J., Sattabongkot, J., Jones, J., Bjørnstad, O.N., Yan, G. and Cui, L. (2005) Spatio-Temporal Distribution of Plasmodium falciparum and P. vivax Malaria in Thailand. American Journal of Tropical Medicine \& Hygiene, 72, 256-262. 
[17] Hui, F.M., Xu, B., Cheng, Z.W., Cheng, X., Lu, L., Huang, H.B., Fang, L.Q., Hong, Y., Zhou, H.N., Yang, H.L., Zhou, X.N., Cao, W.C. and Peng, G. (2009) Spatio-Temporal Distribution of Malaria in Yunnan Province, China. American Journal of Tropical Medicine \& Hygiene, 81, 503-509.

[18] Wen, L., Li, C., Lin, M., Yuan, Z., Huo, D., Li, S., Wang, Y., Chu, C., Jia, R. and Song, H. (2011) Spatio-Temporal Analysis of Malaria Incidence at the Village Level in a Malaria-Endemic Area in Hainan, China. Malaria Journal, 10, 88. http://dx.doi.org/10.1186/1475-2875-10-88

[19] Carter, R., Mendis, K.N. and Roberts, D. (2000) Spatial Targeting of Interventions against Malaria. Bulletin of the World Health Organization, 78, 1401-1411.

[20] Sullivan, D. (2010) Uncertainty in Mapping Malaria Epidemiology: Implications for Control. Epidemiologic Reviews, 32, 175-187. http://dx.doi.org/10.1093/epirev/mxq013 